\title{
Coronavirus Disease 2019 and Cold Agglutinin Syndrome: An Interesting Case
}

\author{
Ruby Gupta ${ }^{1}$, Sukhmani Singh ${ }^{1}$, Nwabundo Anusim ${ }^{1}$, Sachin Gupta $^{2}$, Sorab Gupta ${ }^{3}$, Marianne Huben ${ }^{1}$, George Howard ${ }^{1}$, Ishmael Jaiyesimi ${ }^{1}$ \\ ${ }^{1}$ William Beaumont Hospital, Department of Hematology and Medical Oncology, Royal Oak, Michigan, USA \\ ${ }^{2}$ Reading Hospital, Department of Internal Medicine, Reading, Pennsylvania, USA \\ ${ }^{3}$ Bronx Care Hospital, Department of Hematology and Medical Oncology, Bronx, NY, USA
}

Received: $11 / 02 / 2020$

Accepted: $17 / 02 / 2021$

Published: $10 / 03 / 2021$

How to cite this article: Gupta R, Singh S, Anusim N, Gupta S, Gupta S, Huben M, Howard G, Jaiyesimi I. Coronavirus disease 2019 and cold agglutin syndrome: an interesting case. EJCRIM 2021;8: doi:10.12890/2020_002387.

Conflicts of Interests: The Authors declare that there are no competing interests.

This article is licensed under a Commons Attribution Non-Commercial 4.0 License

\section{ABSTRACT}

The coronavirus disease 2019 (COVID-19) pandemic has caused significant morbidity and mortality worldwide. While patients with COVID-19 most frequently present with pneumonia, respiratory failure and acute respiratory distress syndrome, increasing cases of immunemediated disorders such as autoimmune thrombocytopenia, haemolytic anaemia and antiphospholipid syndrome have been reported. In this article we describe a rare case of cold agglutinin syndrome (CAS) in a patient with COVID-19. The patient was a 77-year-old man with a history of glucose-6-phosphate dehydrogenase (G6PD) deficiency who presented with COVID-19 infection and acute respiratory failure. Initially he was started on intravenous steroids, antibiotics and hydroxychloroquine. Laboratory analysis revealed haemolytic anaemia with a positive direct anti-globulin test (DAT) and high titres of cold agglutinins. Hydroxychloroquine was stopped due to suspicion of haemolysis due to G6PD deficiency but the haemolysis persisted. Unfortunately, the respiratory failure progressed and the patient died. In summary, this article describes a rare case of CAS associated with COVID-19. CAS is a heterogenous group of cold autoimmune haemolytic anaemias occurring secondary to infections or malignancies. No definite treatment for CAS in COVID-19 patients has been approved so far.

\section{LEARNING POINTS}

- Autoimmune haemolytic anaemia has been reported in COVID-19 patients.

- Cold agglutinin syndrome (CAS) can occur in patients with COVID-19.

- Efforts to determine the optimal management of CAS in COVID-19 patients must continue.

\section{KEYWORDS}

Coronavirus disease 2019, cold agglutinin syndrome, case report, autoimmune hemolytic anemia

\section{INTRODUCTION}

Severe acute respiratory syndrome coronavirus 2 (SARS-CoV-2) is a novel enveloped RNA betacoronavirus that emerged in December 2019 in Wuhan, China and rapidly spread worldwide ${ }^{[1]}$. This virus is responsible for causing a multi-system disorder called coronavirus disease 2019 (COVID-19) syndrome. It has now been established that the hyperinflammatory response induced by SARS-CoV-2 causing fulminant and fatal cytokine release is a major cause of disease severity and death in infected patients ${ }^{[2,3]}$. While hypercoagulability ${ }^{[4]}$, autoimmune cytopenias ${ }^{[5]}$ and anti-phospholipid antibody syndrome ${ }^{[4]}$ have emerged as the most common haematological disorders in 
COVID-19 patients, 14 cases of autoimmune haemolytic anaemiahave also been reported ${ }^{[6-12]}$.

Individuals with autoimmune haemolytic anaemiaproduce warm, coldor mixed-reactive antibodiesthat are directed against antigens on the surface of red blood cells (RBCs) ${ }^{[13]}$.Cold antibody autoimmune haemolytic anaemias can be further divided into cold agglutinin disease (CAD), which is primarily a low-grade clonal lymphoproliferative disorder, and cold agglutinin syndrome (CAS), which is a rare heterogenous group of cold immune haemolytic anaemias that occur secondary to infection or malignancy ${ }^{[14]}$.

Here, we report a case of acute CAS associated with SARS-CoV-2.

\section{CASE DESCRIPTION}

A 77-year-old African American man with multiple medical comorbidities including COPD and glucose-6-phosphate dehydrogenase (G6PD) deficiency, presented to the emergency department (ED) with complaints of fever, mild cough, shortness of breath, chills and decreased appetite. In the ED, his vital signs were: blood pressure $127 / 50 \mathrm{mmHg}$, pulse rate $66 \mathrm{bpm}$, respiratory rate 18 breaths per minute, and temperature $98.7^{\circ} \mathrm{F}$; his oxygen saturation $\left(\mathrm{SaO}_{2}\right)$ was $96 \%$ on room air. The initial physical examination was unremarkable. The laboratory findings on admission included sodium $132 \mathrm{mmol} / \mathrm{l}, \mathrm{CO}_{2} 17 \mathrm{mmHg}$, glucose $196 \mathrm{mg} / \mathrm{dl}$, BUN $30 \mathrm{mg} / \mathrm{dl}$, creatinine $1.8 \mathrm{mg} / \mathrm{dl}, \mathrm{GFR} 41 \mathrm{ml} /$ $\mathrm{min} / 1.73 \mathrm{~m}^{2}$, white blood cell count $7.8 \times 10^{9} / \mathrm{l}$, haemoglobin $8.8 \mathrm{~g} / \mathrm{dl}$, haematocrit $27.1 \%$, lymphocyte count $0.4 \times 10^{9} / \mathrm{l}$, and platelet count $147 \times 10^{9} /$; total bilirubin was $1.9 \mathrm{mg} / \mathrm{dl}$ (compared with $1.1 \mathrm{mg} / \mathrm{dl} 3$ months previously). The patient tested positive for COVID-19 with the nucleic acid amplification test. He was found to have a ferritin level of $1484 \mathrm{ng} / \mathrm{ml}$. The chest x-ray in the ED showed no acute process in the lungs. He was started on intravenous fluids.

On day 3 , the patient desaturated to $85 \%$ on room air and was placed on supplemental oxygen via a nasal cannula at $6 \mathrm{l} / \mathrm{min}$. However, he continued to desaturate, resulting in the placement of a non-rebreather (NRB) mask at $15 \mathrm{l} / \mathrm{min}$. Physical examination at this time showed the development of 1+ pitting oedema in the lower extremities bilaterally, and diminished breath sounds at the lung bases. The patient was started on a 7-day course of IV methylprednisolone 40 mg every 12 hours.

On day 4, he was weaned to a 6-litre nasal cannula.However,on day 5 he experienced further episodes of desaturation and was placed back on the NRB mask and was given hydroxychloroquine $400 \mathrm{mg}$ twice a day on the first day followed by $200 \mathrm{mg}$ twice a day for 3 days and azithromycin $250 \mathrm{mg}$ for 5 days. Laboratory findings on day 4 were significant for LDH 439 units/l, D-dimer $596 \mathrm{ng} / \mathrm{mland}$ CRP $115 \mu \mathrm{l} / \mathrm{ml}$. Thepatient was also started on IV cefepime for suspected hospital-acquired pneumonia.

On day 8, the patient continued to have worsening hypoxia on a 25-litre NRB mask and cold mist, and so was switched to 7 litres of cool mist plus a 15-litre NRB mask. He was also re-started on systemic steroids for his evolving inflammatory state.

On day 9, work-up for the persistent anaemia showed a positive Coomb's test for anti-C3d antibody, while the cold agglutinin titre result from day 12 was 1:256, consistent with the diagnosis of cold agglutinin haemolytic anaemia. A peripheral smear was consistent with cold agglutination in the setting of lymphocytosis. The peripheral smear demonstrating agglutination is shown in Fig. 1. Haemoglobin (7.4 g/dl) and haematocrit (20.6) were low, while indirect bilirubin ( $3.3 \mathrm{mg} / \mathrm{dl}$ ) was elevated. LDH (800 units/l) was also elevated, while haptoglobin $(200 \mathrm{mg} / \mathrm{dl})$ was within the normal range. Epstein-Barr virusand mycoplasma antibody tests were negative for acute infection. Normocytic, normochromic anaemia was found with marked RBC agglutination that resolved with warming. On the warmed slides, polychromasia, spherocytes, ovalocytes and occasional nucleated RBCs were found. Hydroxychloroquine (given days on 5-7) causing G6PD-deficiencyrelated haemolysis was initially suspected but not confirmed and the drug was discontinued for this reason. Deep vein thrombosis (DVT) prophylaxis enoxaparin was started as per our institutional protocol.

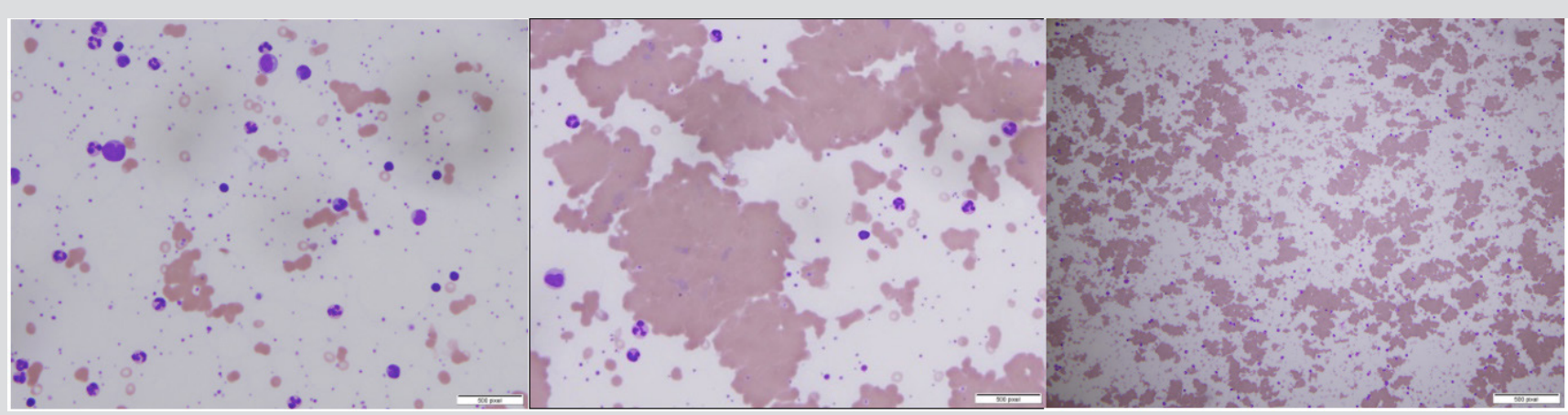

Figure 1. Peripheral smear demonstrating cold agglutination 
On day 10, haemoglobin dropped further to $5.9 \mathrm{~g} / \mathrm{dl}$ and haematocrit to 17.7 . The patient received 2 units of packed RBCs bringing haemoglobin back to $7.9 \mathrm{~g} / \mathrm{dl}$ the next day.

On day 12, the patient was intubated due to worsening hypoxia.

On day 13 , he developed worsening renal failure requiring continuous renal replacement therapy due to acute kidney injury. He was started onmeropenem.

On day 16, he was given a blood transfusion due to low haemoglobin of $4.1 \mathrm{~g} / \mathrm{dl}$. Since haemolysis worsened despite the cessation of hydroxychloroquine, COVID-19 appeared to be the major cause of cold agglutinin haemolytic anaemia. Unfortunately, the patient's blood pressure continued to drop despite the use of pressors and he died.

The patient's laboratory data are shown in Table 1.

\begin{tabular}{|c|c|c|c|c|c|}
\hline & Day 1 & Day 5 & Day 9 & Day12 & Day 16 \\
\hline \multicolumn{6}{|c|}{ COVID-19-related parameters } \\
\hline Ferritin (ng/ml) & 1484 & & 6169 & 3720 & \\
\hline LDH (units/l) & & 439 & 800 & 1015 & \\
\hline D-dimer $(\mathrm{ng} / \mathrm{ml})$ & & 596 & 3590 & 5344 & $>10,000$ \\
\hline $\operatorname{CRP}(\mu \mathrm{l} / \mathrm{ml})$ & & 115.5 & 130.6 & 133.4 & \\
\hline \multicolumn{6}{|l|}{ Other laboratory data } \\
\hline WBC $\left(\times 10^{9} / 1\right)$ & 7.8 & 24.3 & 40.6 & 43.9 & 38.7 \\
\hline Haemoglobin (g/dl) & 8.8 & 8.5 & 7.4 & 7.9 & 4.1 \\
\hline Haematocrit(\%) & 27.1 & 26.7 & 20.6 & 17.7 (day 11) & 13.7 \\
\hline Platelets $\left(\times 10^{9} / \mathrm{I}\right)$ & 147 & 248 & 473 & 479 & 132 \\
\hline $\operatorname{ANC}\left(\times 10^{3} / \mu l\right)$ & 6.1 & 19.5 & 23.4 & 27.7 & 42.4 \\
\hline $\operatorname{ALC}\left(\times 10^{9} / \mathrm{l}\right)$ & 0.4 & 2.7 & 11.5 & 11.8 & 19.9 \\
\hline Cold agglutinin titre & & & & $1: 256$ & \\
\hline Haptoglobin (mg/dl) & 217 & & 200 & 154 (day 11) & \\
\hline Total bilirubin ( $\mathrm{mg} / \mathrm{dl})$ & 1.9 (day 2) & 3.6 & 6.6 & 3.7 & 6.6 \\
\hline Indirect bilirubin (mg/dl) & & & 3.3 & 1.8 & 2.7 \\
\hline BUN (mg/dl) & 30 & 63 & 77 & 105 & 26 \\
\hline Creatinine (mg/dl) & 1.8 & 1.93 & 1.82 & 1.93 & 1.5 \\
\hline
\end{tabular}

Table 1. Summary of laboratory data

\section{DISCUSSION}

Cold agglutinin haemolytic anaemia in COVID-19 patients appears to be a rare phenomenon. Fourteen cases of either warm or cold agglutinin autoimmune haemolytic anaemia have been reported in patients with COVID-19 ${ }^{[6-12]}$ as well as Evans syndrome ${ }^{[15]}$. Our patient deteriorated quite rapidly despite the medical interventions. Although he receivedthe relevant diagnostic tests, optimal critical care support and pharmacological interventions, he unfortunatelydied, indicating that we need to continue our efforts to find effective treatments for this disease.

\section{CONCLUSION}

COVID-19 has emerged as a multi-system disease. CAS is a rare disorder found in patients with COVID-19. As no definite treatment for CAS in COVID-19 patients has been approved so far,we need to continue our efforts to determine the optimal management of this condition. 


\section{REFERENCES}

1. Pal M, Berhanu G, Desalegn C,et al. Severe acute respiratory syndrome coronavirus-2 (SARS-CoV-2): an update. Cureus 2020;12(3):e7423.

2. Mehta P, McAuley DF, Brown M, et al. COVID-19: consider cytokine storm syndromes and immunosuppression. Lancet 2020;395:1033-1034.

3. Haigh K, Syrimi ZJ, Irvine S,et al. Hyperinflammation with COVID-19: thekey to patient deterioration? Clin Infect Pract 2020;7-8:100033.

4. Zhang Y, Xiao M, Zhang S, et al. Coagulopathy and antiphospholipid antibodies in patients with Covid-19. N Engl J Med 2020;382:e38.

5. Zulfiqar A-A, Lorenzo-Villalba N, Hassler P,et al.Immune thrombocytopenic purpura in a patient with Covid-19. N Engl J Med 2020;382:e43.

6. Lazarian G, Quinquenel A, BellalM, et al. Autoimmune haemolytic anaemia associated with COVID-19 infection. Br J Haematol 2020;190(1):29-31.

7. Zagorski E, Pawar T, Rahimian S,et al. Cold agglutinin autoimmune haemolytic anaemia associated with novel coronavirus (COVID-19). Br J Haematol 2020;190(4):e183-e184.

8. Hindilerden F, Yonal-Hindilerden I, Akar E, Yesilbag Z, Kart-Yasar K. Severe autoimmune hemolytic anemiain COVID-19 infection, safely treated with steroids.Mediterr J Hematol Infect Dis 2020;12(1):e2020053.

9. Jacobs J, Eichbaum Q. COVID-19 associated with severe autoimmune hemolytic anemia. Transfusion 2020;61(2):635-640.

10. Jawed M, Hart E, Saeed M. Haemolytic anaemia: a consequence of COVID-19. BMJ Case Rep 2020;13(12):e238118.

11. Campos-Cabrera G, Mendez-Garcia E, Mora-Torres M, et al. Autoimmune hemolytic anemia as initial presentation of COVID-19 infection. Blood 2020;136(Suppl 1):8.

12. Capes A, Bailly S, Hantson P, Gerard L, Laterre PF. COVID-19 infection associated with autoimmune hemolytic anemia. Ann Hematol 2020;99(7):1679-1680.

13. Berentsen, S, Ulvestad, E, Langholm, R, et al. Primary chronic cold agglutinin disease: a population based clinical study of 86 patients. Haematologica 2006 ; 91 (4):460-466.

14. Berentsen, S. New insights in the pathogenesis and therapy of cold agglutinin-mediated autoimmune hemolytic anemia. Front Immunol 2020;11:590.

15. Li M, Nguyen C, Yeung Z,et al. Evans syndrome in a patient with Covid-19. Br J Haematol 2020;190(2):e59-e61. 